\title{
Wear and Fretting Behavior of Cold Sprayed IN625 Superalloy
}

\author{
Pasquale Daniele Cavaliere ${ }^{1, *(\mathbb{D}}$, Antonella Rizzo ${ }^{2}$, Daniele Valerini ${ }^{2} \mathbb{D}$ and Laura Capodieci ${ }^{2}$ \\ 1 Department of Innovation Engineering, University of Salento, 73100 Lecce, Italy \\ 2 ENEA-Italian National Agency for New Technologies, Energy and Sustainable Economic Development, \\ Brindisi Research Centre, S.S. 7 Appia, km 706, 72100 Brindisi, Italy; antonella.rizzo@enea.it (A.R.); \\ daniele.valerini@enea.it (D.V.); laura.capodieci@enea.it (L.C.) \\ * Correspondence: pasquale.cavaliere@unisalento.it; Tel.: +39-0832-297-357
}

\section{check for updates}

Citation: Cavaliere, P.D.; Rizzo, A.; Valerini, D.; Capodieci, L. Wear and Fretting Behavior of Cold Sprayed IN625 Superalloy. Metals 2021, 11, 49. https://doi.org/10.3390/met11010049

Received: 9 November 2020 Accepted: 19 December 2020 Published: 28 December 2020

Publisher's Note: MDPI stays neutral with regard to jurisdictional claims in published maps and institutional affiliations.

Copyright: () 2020 by the authors. Licensee MDPI, Basel, Switzerland. This article is an open access article distributed under the terms and conditions of the Creative Commons Attribution (CC BY) license (https: / / creativecommons.org/ licenses/by/4.0/).

\begin{abstract}
The wear and fretting behaviour of IN625 cold spray coatings was analysed and the results are presented. The cold spray conditions were selected in order to obtain coatings with minimum porosity and maximum particles splat. This leads to compact and hard deposited material able to resist wear damaging and to dissipate energy during fretting. The coating's strength was evaluated through nanoindentation that revealed an increased hardness from the surface toward the substrate. This different hardening behaviour from the coating surface toward the substrate leads to increased resistance to fretting and wear as the maximum stresses increase. This was revealed by scratch tests performed at linearly increasing loads that allowed identifying of the damage mechanisms acting on the coating as the triaxial stresses increase. The hardening behaviour of the coating also influenced the fretting behaviour revealed by the weight loss experienced by varying the fretting maximum load.
\end{abstract}

Keywords: cold spray; nanoindentation; scratch; fretting; wear

\section{Introduction}

Cold spray is a well-known and defined additive manufacturing technology mainly aimed at the production of sound and high resistant coatings [1,2]. Metallic or composite particles are accelerated through a high pressure gas at temperatures well below the materials' melting points. The impacting particles experience severe plastic deformation once they reach the substrate. This feature activates many microstructural modifications leading to the particle-substrate bonding and the particle-particle cohesion [3]. A particle deformation mode, during cold spray, is dependent on various factors such as material properties, geometries and spray parameters; each factor is also dependent on different particular conditions. The modification of any of these conditions allows obtaining of different microstructures and consequent mechanical properties of the coating [4]. Obviously, it is largely demonstrated that the coating's overall properties are strictly dependent on the processing parameters employed during spraying [5,6]. As a matter of fact, some papers revealed that cohesion is connected to the prominent role of adiabatic shear instability. Under these conditions, the temperature rises and both the particle and substrate behave like a viscous material, which results in the metal jet at the rim of deformed area; it can disrupt thin oxide films on the surface of the material $[7,8]$. The resulting oxide-free surface can provide an optimal particles-substrate contact; then metallurgical bonding occurs at the particle/substrate interface under high local pressure. Anyway, other authors observed that cold spray leads to jetting formation as a consequence of the strong pressure waves that interact with the particle edge upon contact [9]. It is widely believed that many additional experimental and numerical evidences are needed in order to arrive at a conclusive milestone. Referring to pure metals, with varying the spray conditions, the deformation mode and the microstructural evolution of the splatted material strongly changes [10-12]. Depending on the particles' properties and on the spray conditions, the 
coating's microstructure and mechanical properties are largely influenced with different responses to external loads, especially to those acting on the surface. The metallurgical bonding is improved by plastic deformation that is revealed by the particle's flattening ratio at different distances from the substrate $[13,14]$.

Cold spray can be employed as final coating to additive manufacturing and repair of a broad variety of Ni-based alloy turbine blades [15]. In addition, the possibility of depositing coatings on less expensive substrates represents a big advantage in design and manufacturing [16].

Nickel superalloys are employed as coating materials in order to improve wear and strength of metallic components. These alloys are used in very wide fields also because of the resistance to corrosive attacks in very broad temperature ranges [17]. The surface degradation leads to crack nucleation and growth in the coatings; consequently, wear and fretting damage must be taken into account in the design of these kinds of coatings $[18,19]$. The wear and fretting behaviour of cold spray coatings is less investigated with respect to other properties. All the available data are mainly related to dry wear characterized by traditional techniques [20]. As a general behaviour, the wear resistance is governed by the coating porosity and hardness [21].

In many accepted theories, the material wear behaviour is based on the hardness of the surface as the only fundamental parameter. More recently, it was demonstrated that an additional parameter to be taken into account is the elastic modulus; only in this way it is possible to precisely define the wear evolution of a surface under sliding. In particular, the hardness-elastic modulus ratio is capable of providing a definitive explanation of the overall wear behaviour. In this regard, nanoindentation allows for the measurement of hardness and elastic modulus in very small volumes also leading to the mapping of mechanical properties at the level of very thin films [22]. During nanoindentation and nanoscratch the applied load and the consequent indenter depth is continuously measured; this allows for the continuous evaluation of the tribology of the material under investigation [23].

To the best of the authors' knowledge, no data are available in literature on the nanoscratch deformation mechanisms of cold spray coatings or information about the fretting wear behaviour of cold sprayed nickel superalloys. The fretting wear alone, is a complicated phenomenon to give a conclusive description of the damage behaviour of cold sprayed coatings [24]. Here, nanoindentation tests were employed to measure the surface mechanical properties of the coating as well as their variation along the distance from the surface toward the substrate. Scratch tests were employed in order to monitor the deformation modes of the material upon sliding. Though the microstructural observations of the scratch traces it was possible to identify different incoming deformation mechanisms as the load acting on the coating increases. The deformation modes evolution allowed obtaining of very useful information for the development of sound cold spray coatings with optimized strength and thickness. The fretting behaviour of the cold sprayed IN625 was analysed.

\section{Experimental Procedure}

The feedstock powder was PG-AMP-1060 type, from Plasma Giken Co. Ltd., Saitama, Japan (wt\%: Cr 22.0; Mo 2.0; Fe 2.0; Ta 1.0; Ni bal.) with particle size distribution in the range -25 to $-20 \mu \mathrm{m}$. The nominal particles material hardness was $4.7 \pm 1.1 \mathrm{GPa}$.

The coatings were obtained by cold gas spray (CGS) process, employing the CGT Kinetics 4000 (Cold Gas Technology GMBH, Haun, Germany) with a SiC nozzle, with rectangular cross Section $2 \mathrm{~mm} \times 4 \mathrm{~mm}$ throat and $2 \mathrm{~mm} \times 10 \mathrm{~mm}$ exit. The coatings were produced via cold spray by employing nitrogen as carrier gas. The processing conditions were $800{ }^{\circ} \mathrm{C}$ in temperature, $40 \mathrm{bar}$ in pressure and $40 \mathrm{~mm}$ in stand-off distance. The coatings were deposited to a final thickness of $500 \mathrm{~m}$ on carbon steel. LeicaDMI 5000M (Leica Microsystems, Wetzlar, Germany) was employed for optical microscopy observations. The coatings surface was polished with diamond paper before nanomechanical tests and microstructural observations. Image J software (https:/ /imagej.nih.gov/) was employed to 
elaborate the microscope images and calculate the porosity of the coatings in a transversal direction. The splatted particle's microstructure observations were possible after immersion in aqua regia (nitric acid hydrochloric acid in a molar ratio of 1:3) for $25 \mathrm{~s}$. Computational fluid dynamics (CFD) software Fluent 16.2 (ANSYS FLUENT, Canonsburg, PA, USA) was employed for the spraying process modelling in order to calculate the particles' velocities upon impact. A supersonic nozzle with expansion ratio of 5.6 was modelled and meshed in order to perform 2-D axis-symmetric analyses using a density based algorithm to make convergence of the solutions. In the cold spray process, very high impact velocities are recorded. Due to this aspect, the $k-\varepsilon$ algorithm was employed to calculate the effect of the turbulences on the effective area of the nozzle. The calculations were performed in different spray conditions in order to improve the particles' velocities in the experiments.

The nanomechanical properties of the coatings were studied through an Anton Paar nanoindenter model TTX-NHT2 (Anton Paar GmbH, Graz, Austria), equipped with a Berkovich diamond indenter (Anton Paar $\mathrm{GmbH}$, Graz, Austria). The tests were performed under load control at a maximum load of $500 \mathrm{mN}$, linear loading and unloading rate of $1000 \mathrm{mN} / \mathrm{min}$, and a dwell time of $5 \mathrm{~s}$. Eleven indentations per sample were performed on the top surface of the coatings and the average values were recorded. In addition, nanoindentations were performed on the transversal section in order to monitor the mechanical properties' variations through the thickness. Hardness and elastic modulus were calculated by Oliver and Pharr methods on the indentation load versus depth curves.

Scratch tests were performed by using an Anton Paar Revetest instrument (Anton Paar $\mathrm{GmbH}$, Graz, Austria) with a Rockwell-C diamond indenter (Anton Paar GmbH, Graz, Austria) on the coating's surface. The normal load was linearly applied in the range $1-200 \mathrm{~N}$ over a scratch length of $10 \mathrm{~mm}$ at a speed of $50 \mathrm{~mm} / \mathrm{min}$.

The morphology of the surface was analyzed by FE-SEM, on a Field Emission Scanning Electron Microscope ZEISS Merlin (ZEISS, Oberkochen, Germany) equipped with a GEMINI II column and Beam-Booster (ZEISS, Oberkochen, Germany), with acceleration voltages between 0.05 and $30 \mathrm{kV}$ and $0.8 \mathrm{~nm}$ as the best resolution, for optional detectors for secondary electron (SE) and back scattered electron (BSE), charge compensation and an in situ sample cleaning system.

The fretting wear resistance of samples was evaluated by Nanovea Tribometer T500 (NANOVEA, Irvine, CA, USA) using the linear reciprocating wear module. An image processing system complete with camera mounted on an optical microscope (NANOVEA, Irvine, CA, USA), equipped with analysis of traces of wear, measurement of dimensions and to obtain information on the interaction between pin and sample. The profilometer DEktakXT (Bruker, Billerica, MA, USA) allows you measure the width and depth of the tracks, as well as the average height of the peaks measured on the bottom. Once these measurements have been made, it is possible to obtain the volume of material removed from the surface of the sample. For testing we used tungsten carbide pins characterized by high resistance to wear, shocks and thermal changes. The test is performed in dry mode, in other words, without using any cooling or lubrication means in the contact area between the pin and the sample, this obviously involves heating between the two parts in contact. Fretting tests were performed under the same test conditions for all samples; in particular, the sliding distance was set to $0.09 \mathrm{~mm}$ and the test time equal to $10 \mathrm{~min}$. For each specimen, the tests were performed with loads of 50,100 and $150 \mathrm{~N}$, respectively.

\section{Results and Discussions}

The results belonging to the finite element simulations allowed calculation of the velocity and the temperature of the particles upon impact. They resulted in $811 \mathrm{~m} / \mathrm{s}$ and $468^{\circ} \mathrm{C}$, respectively.

The coatings aspect is shown in Figure 1. 


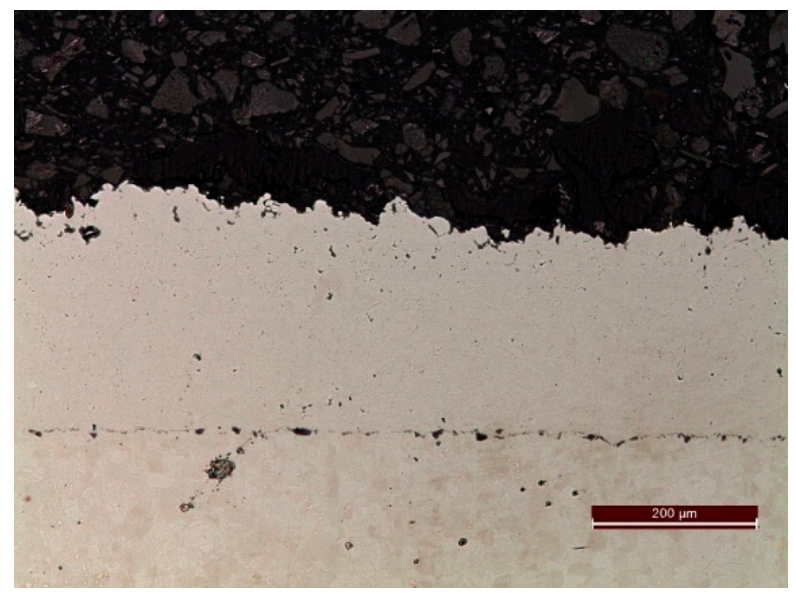

Figure 1. Coatings aspect after spray.

The coating thickness resulted was uniform along all of the substrate surface. The correspondent etched microstructure is shown in Figure 2.
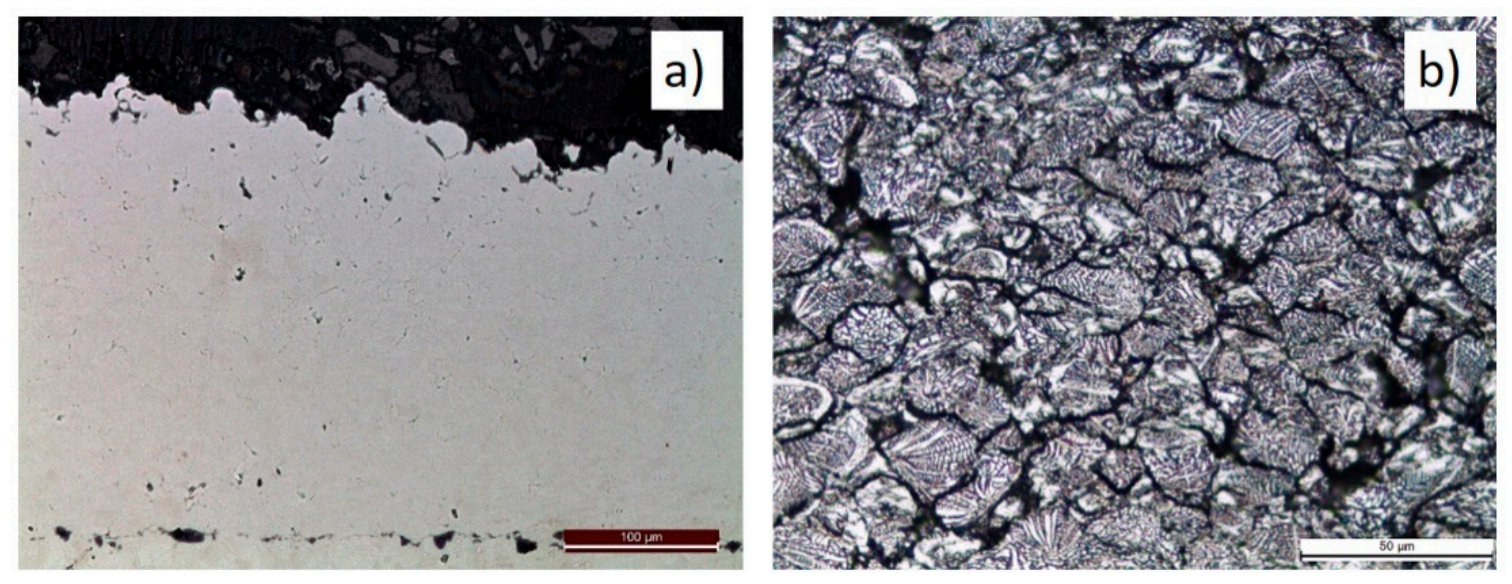

Figure 2. Coating's cross section microstructure after polishing (a) and after etching (b).

The coatings showed a percentage porosity of $1.3 \pm 0.1$ and a mean flattening ratio of $2.6 \pm 0.3$. The porosity results were very low. In general, the flattening ratio increases with the enhancement in the particle's impact velocity as a consequence of the increase in the gas temperature and pressure. By setting an optimal impact velocity leading to high flattening ratio it is also possible to reduce the coating porosity because of the optimal voids filling due to the increased plastic deformation and spat of the particles [25]. High particle energy upon impact favours metallurgical bonding as a consequence of the high plastic deformation. This is accompanied contemporarily with low porosity [10]. In fact, the ability of the material to deform is experienced through the new pancake-like shape with remarkable flattening ratio. If the impact energy is not sufficient, the particle's shape remains almost spherical and many voids remain unfilled during the coating deposition. The impact energy is strongly dependent on the particle velocity and temperature, in particular, it is demonstrated that the porosity reduction has an exponential dependence on the impact temperature [26].

In the traditional wear analyses, hardness is employed as the main factor influencing the surface wear strength. More recently, it was demonstrated that elastic modulus also influences such behaviour especially in the case of hard surfaces. In many scientific evidences, deep analyses of wear behaviour are demonstrated to be governed by the hardness-elastic modulus ratio [27]. In order to measure the mechanical properties of 
the coatings, nanoindentations were employed to characterize the coating surface. The load-depth nanoindentation behaviour of the IN625 surface coatings is shown in Figure 3.

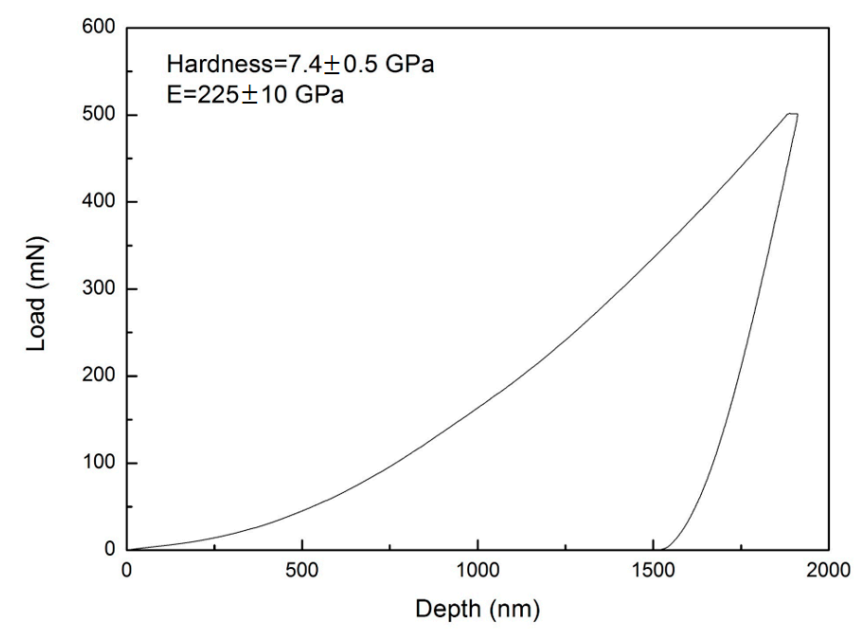

Figure 3. Load-depth indentation curve belonging to the surface of the cold sprayed IN625 coating.

As the indent starts to deform the coating, the strain is purely elastic under very low nanoindentation loads. As the indentation load increases, the curve deviates from the ideal Hertzian behaviour because of the accumulation of the shear stresses at the indentation tip leading to the beginning of the plastic deformation due to the continuous nucleation and slide of the dislocations with pile up revealing the intense plastic deformation around the indent.

Nanoindentations were also performed along the coating thickness. The hardness measurements vs. the coating thickness are shown in Figure 4.

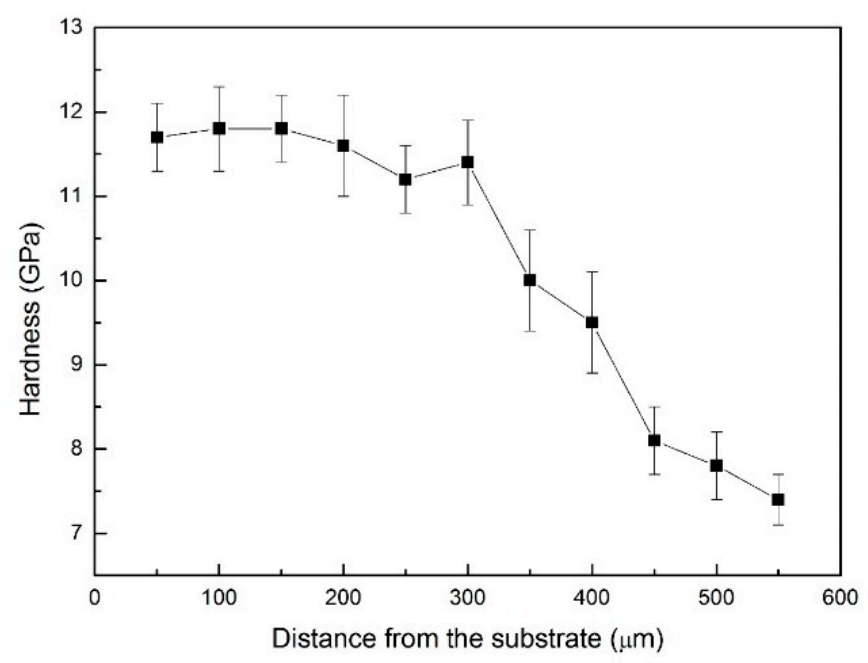

Figure 4. Hardness variation along the coating thickness.

The coating hardness increases by moving from the surface to the substrate. This is due to the continuous deformation due to the progressive impacting particles that continue to harden the previously deposited material until the end of the process. The first sprayed particles impact on the substrate then deform and splat. The further impacting particles continue to deform the previously splatted particles by increasing the severe plastic deformation and reducing the previously formed void. All these phenomena lead to an increase in the material hardness in a crescent manner as the material is closer to the substrate-coating interface. 
Scratch tests were employed to evaluate the strength and adhesion of the coating. The scratch vertical load versus scratch depth belonging to the polished surface is shown in Figure 5 .

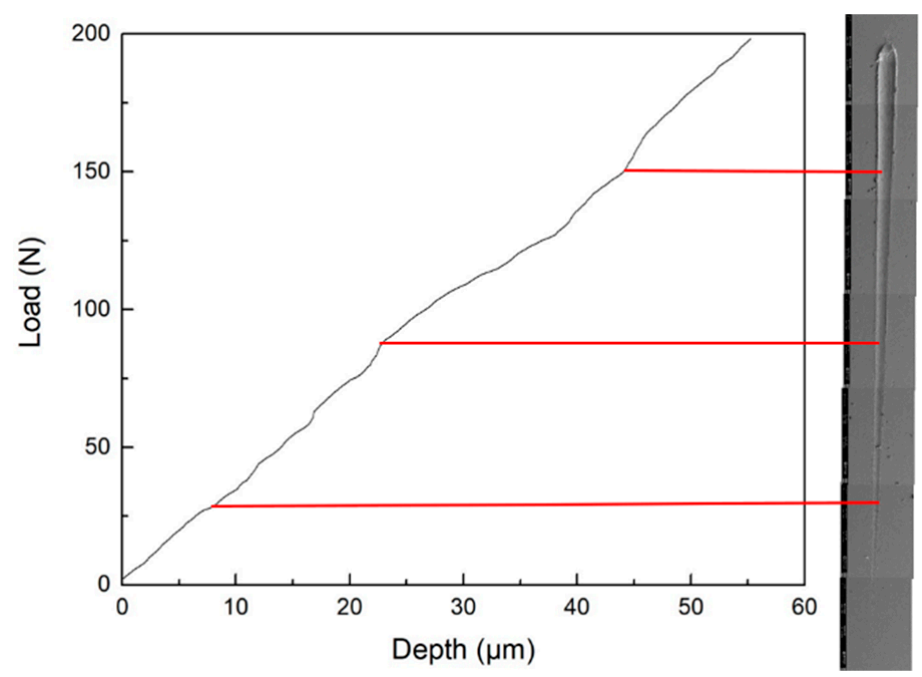

Figure 5. Scratch load vs. penetration depth with the optical aspect of the scratch trace and the indication of critical loads.

The qualitative analyses of the load-depth curves allowed individuation of the so called critical loads (CL). During scratching, the indentation load produces superficial damage leading to the formation of some specific cracks and coating fracture and delamination. The revealing of those loads allows the identification of the critical ones. Once a progressively increasing load is applied, stress increases until incisions occur at specific points along the scratch track. In the present case, these critical points are determined by the incision and detected and recorded through microscopy observations and variations in the friction force. The first critical load (CL1) is thought to act at $28 \mathrm{~N}$ for a scratch depth of $9 \mu \mathrm{m}$. The second critical load acts at $82 \mathrm{~N}$ for a scratch depth of $23 \mu \mathrm{m}$, the last critical load (CL3) is observed at $152 \mathrm{~N}$ for a scratch depth of $44 \mu \mathrm{m}$ (Figure 6). From the comparison with other scratches profiles the deviation from the indicated mean values of critical loads is in the order of $3 \mathrm{~N}$ load and $1.5 \mu \mathrm{m}$ depth. These critical loads divide the load-depth curve into three parts with different slope. This means that the deformation mode changes as the scratch progresses.

By performing the scratch test through the application of a progressive load, it is possible to observe a consecutive series of incisions in the coating as the load increases; the final event usually corresponds to the total delamination of the coating. The critical load depends on the adhesion of the coating as well as on the surface damage mechanisms.

In the present case, the first critical load corresponds to the formation of the first hairline cracks inclined at $30-40^{\circ}$ with respect to the track direction on the coating surface (Figure 6a). This is consistent with previously described deformation modes [28]. This first critical load is normally associated with the first damage mechanisms appearance due to the scratch of the indenter. The damage features appear inclined with respect to the scratch direction because at the beginning of the scratch, the scratch tangential load is predominant on the compression one. In fact, the fracture trend is a function of the elastoplastic properties of the indented material, the geometry of the indenter and the applied load factors [29]. The moment the tool penetrates through the coating, a fracture of the material is generated and a fluctuation of the forces involved. As a matter of fact, inside the scratch groove, many parallel cracks are revealed. These cracks are formed as a consequence of the tensile stresses in front of the indenter during sliding. These microcracks' densities tend to increase as the vertical load increases. 
Once compressive load increases, additional cracks appear in the scratch track as a consequence of the increased compressive stresses. This behaviour is indicated as the second critical load (Figure $6 \mathrm{~b}$ ). The absence of bending cracks reveals that the substrate is sufficiently stiff to absorb the mechanical load. Once macrocracks start to lead to the coating delamination, the coating is believed to be subjected to the third critical load. The delaminations are wing shaped because of the complex multiaxial stress fields acting on the material.

Once the third critical load is reached, the coating is scraped with the appearance of many macrodamages on the surface (Figure 6c). It is well-known that the relationship between the coating hardness and wear behaviour shows also that, by increasing the coating hardness, the worn behaviour shifts from scratches and abrasion type surfaces to steel debris adhering to the coatings. So, the wear resistance, directly related to the coatings hardness, increases. In particular, a parabolic relationship can be underlined between the normalized wear resistance and the normalized coating hardness [30].
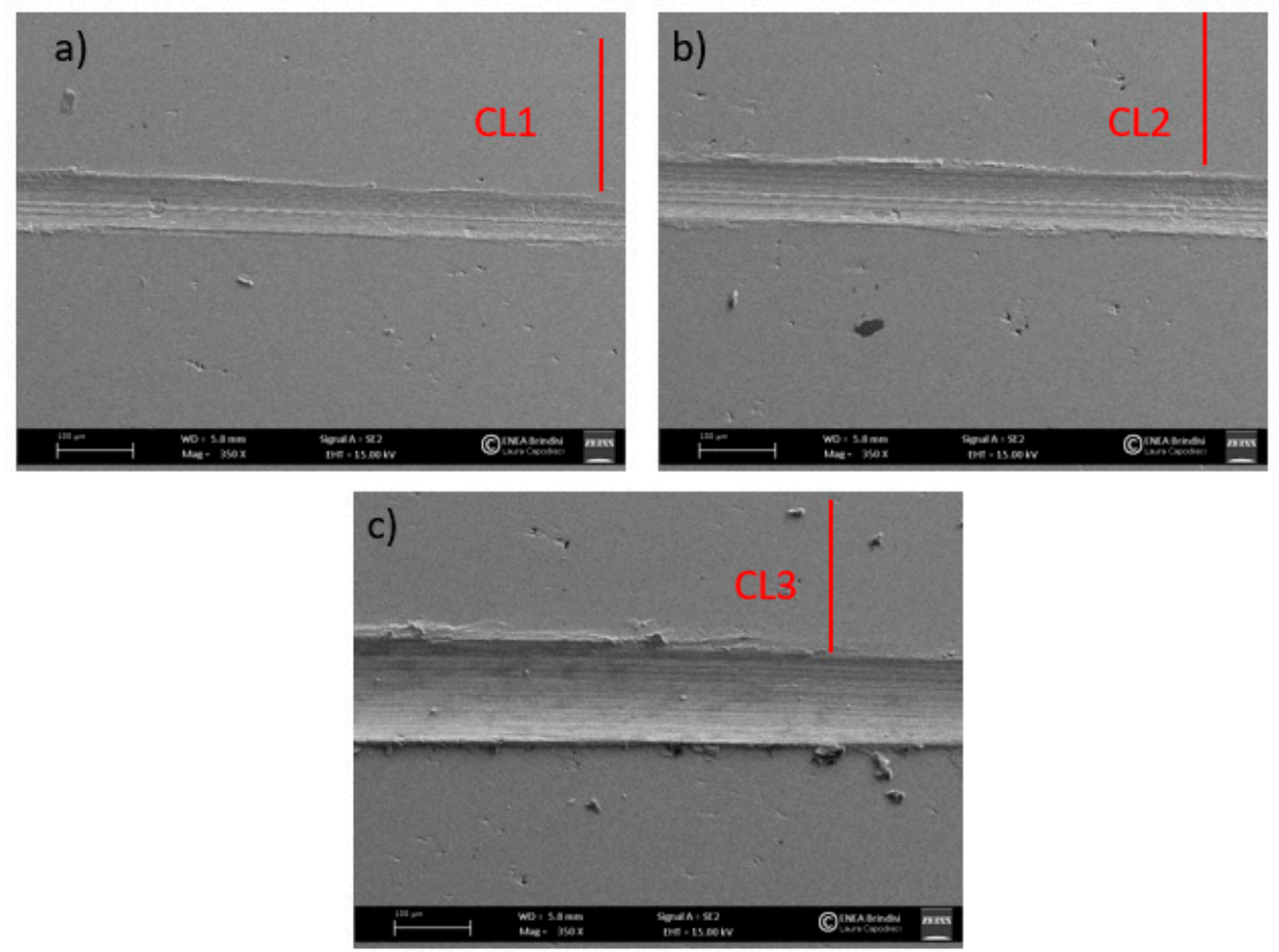

Figure 6. Individuation of critical loads from the scratch tracks in the locations corresponding to the critical load 1 (a), load 2 (b) and load 3 (c).

As a general behaviour, the Ni-based cold spray coating appears very compact with no particle decohesion produced by the increasing of compressive stress during scratch up to the maximum load. As a matter of fact, in Figure 7, the comparison of the scratch aspect at the maximum applied load is shown for the IN625 coating under study and cold sprayed Ti coating in the same conditions and scratched at the same load.

Especially in those applications where nickel based superalloys are employed as coatings, their fretting wear performances analyses results are fundamental [31]. Fretting is the phenomenon of relative oscillatory tangential movement at low amplitude which occurs at materials' interfaces subjected to vibration. By cyclically stressing the surface, the surface damages follow the relative displacements and frequency variations. In general, fretting stresses induce crack initiation and bulk degradation. All the fretting tests were performed at contact loads of 50,100 and 150 N. The wear traces are shown in Figure 8.

The corresponding profiles of the wear rails are shown in Figure 9. 

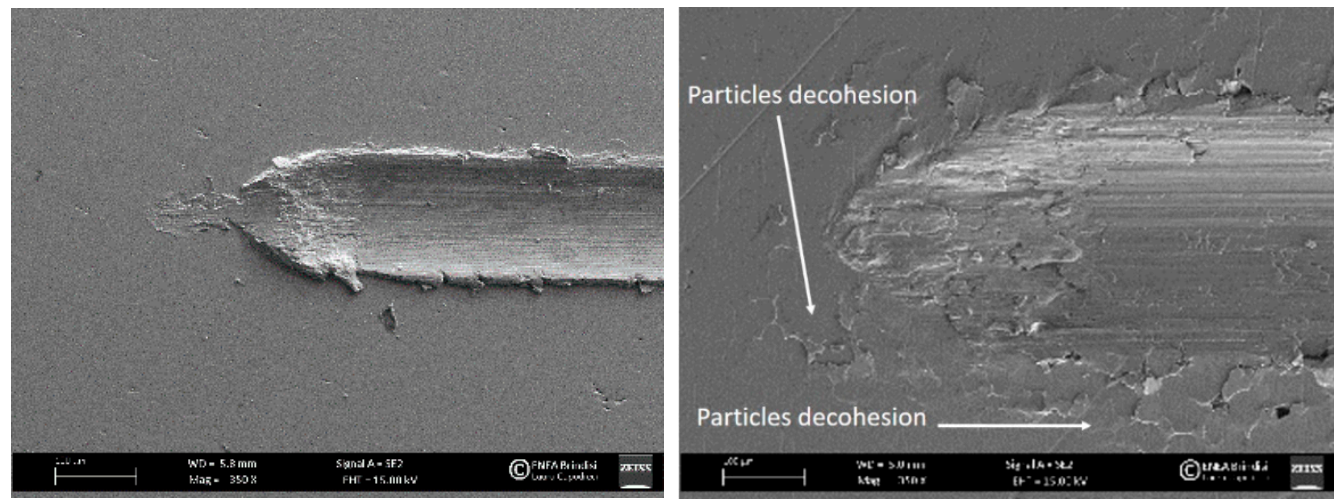

Figure 7. Scratch comparison between the IN625 and pure titanium cold sprayed coatings. The IN625 coating appears very compact at the maximum load (left) while the Ti coating shows particles decohesion around the scratch (right).

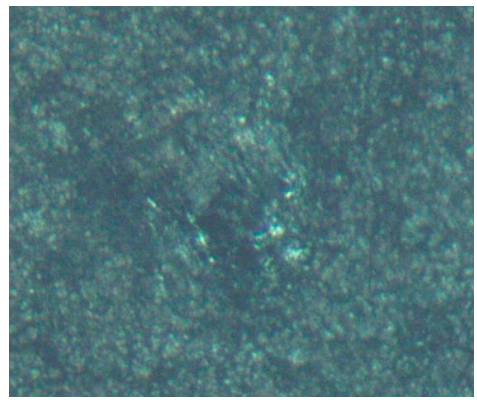

(a)

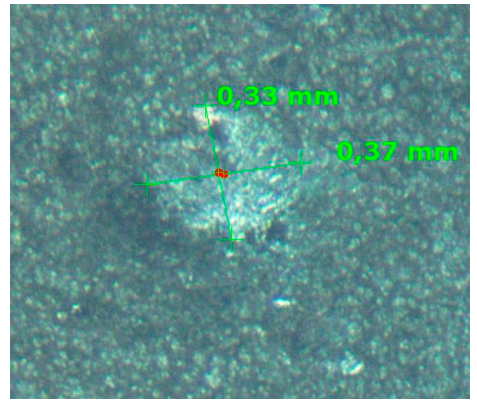

(b)

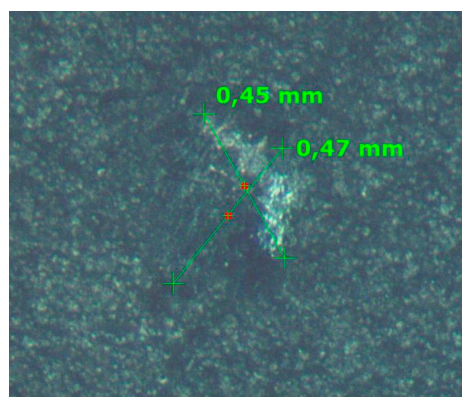

(c)

Figure 8. Optical microscope $10 \times$ images for fretting marks on the Ni_06 surface at loads of 50, 100 and 150 N. (a) Ni_06/WC 50N, (b) Ni_06/WC 100N, (c) Ni_06/WC 150N.
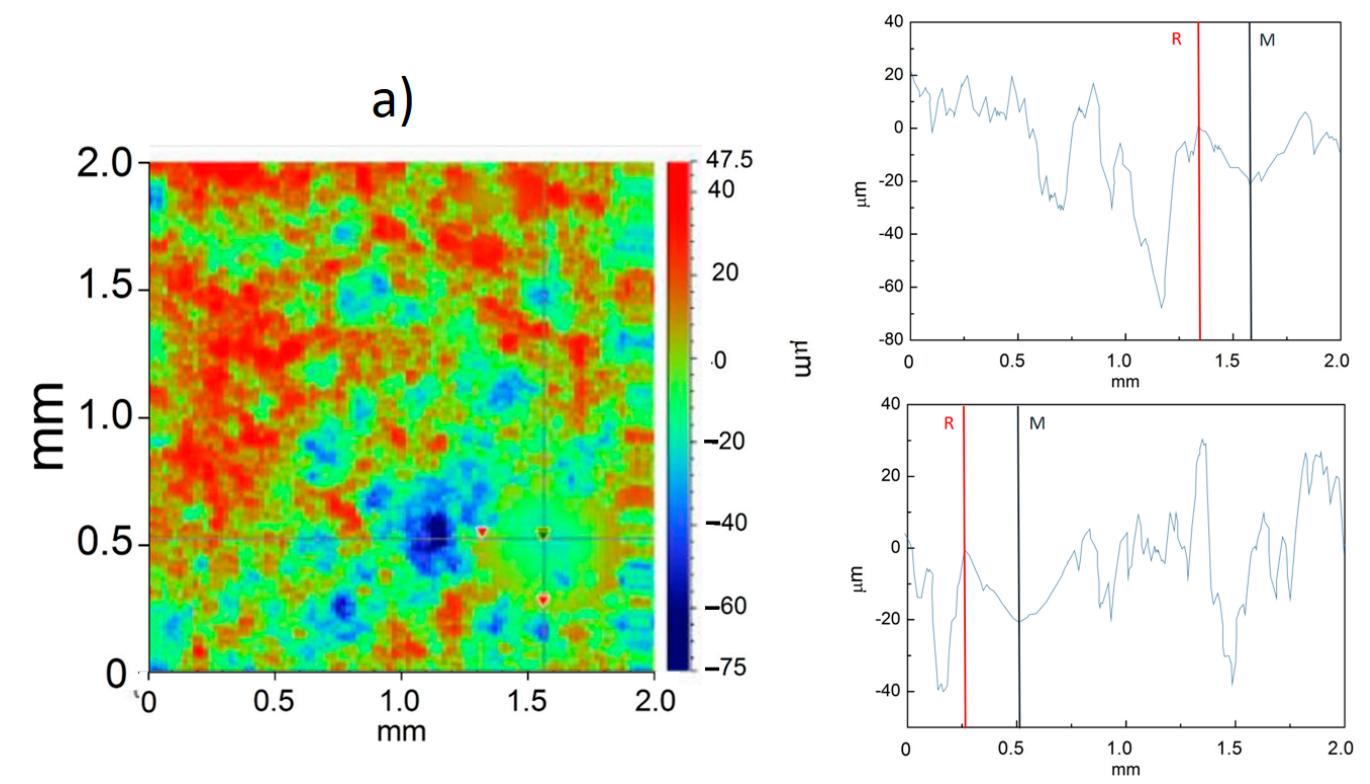

Figure 9. Cont. 

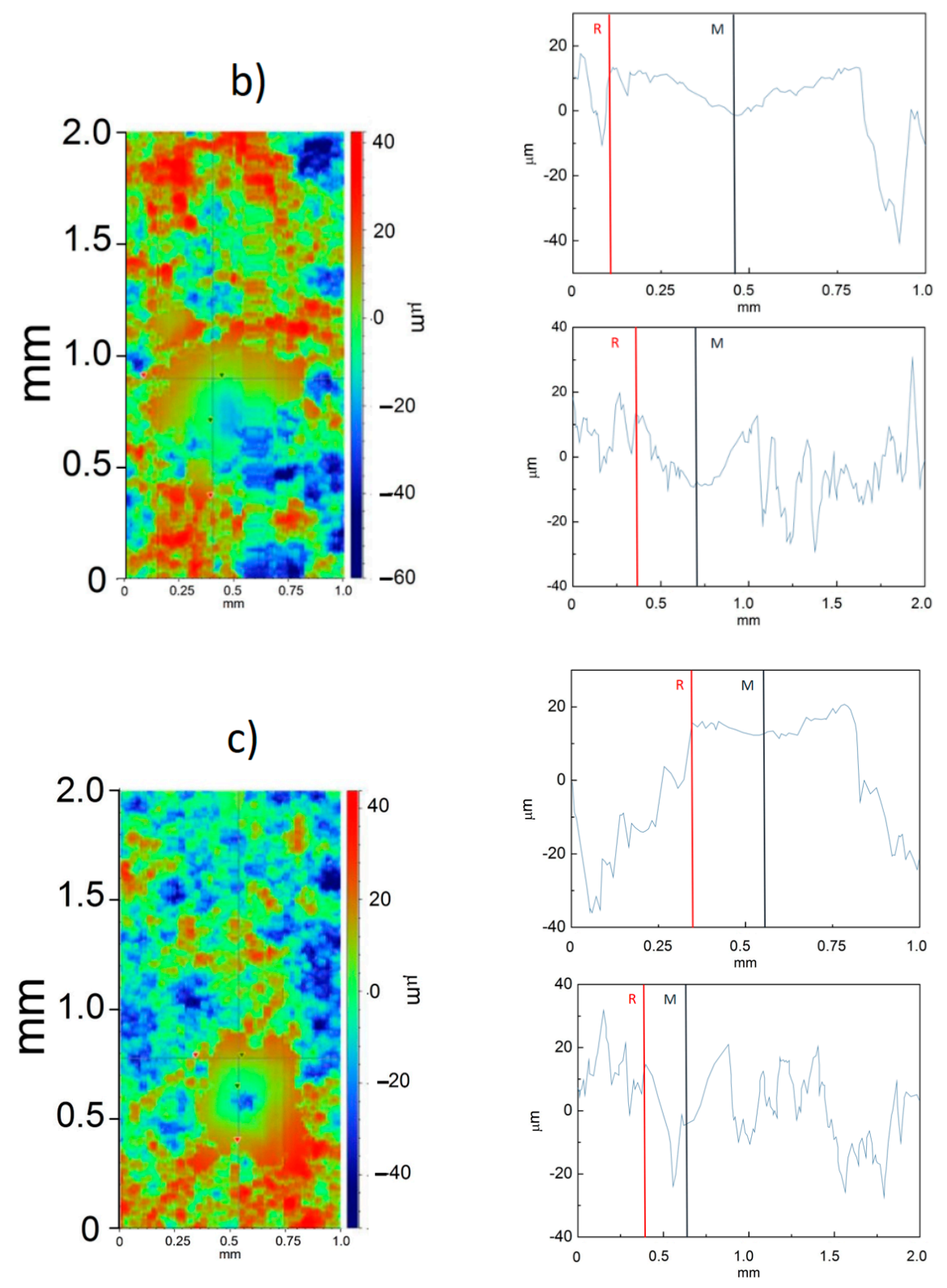

Figure 9. Rails profiles for the wear at the loads of $50 \mathrm{~N}(\mathbf{a}), 100 \mathrm{~N}(\mathbf{b})$ and $150 \mathrm{~N}$ (c).

The wear volume was measured at the end of each test at various loads. As a consequence of the micro wear processes in action, the volume loss is very low. It is calculated from the automatic revealing of the profiles during each test. The corresponding weight loss as a function of the load is shown in Figure 10.

The weight loss increases as the vertical load during wear increases. A net sharp increase is recorded from 50 to $100 \mathrm{~N}$ and then the rate of the weight loss decreases because of the increased resistance of the material by from the surface toward the substrate.

In Figure 11 the regime friction coefficient measured during fretting tests is plotted as a function of the applied load.

In general, the cold spray process allows for very low room temperature friction coefficients. The reduction of the friction coefficient as the maximum load increases is consistent with the measured increased hardness by moving from the coating surface toward the substrate. As a matter of fact, the fretting wear is shown in Figure 12 as a function of the applied load. 


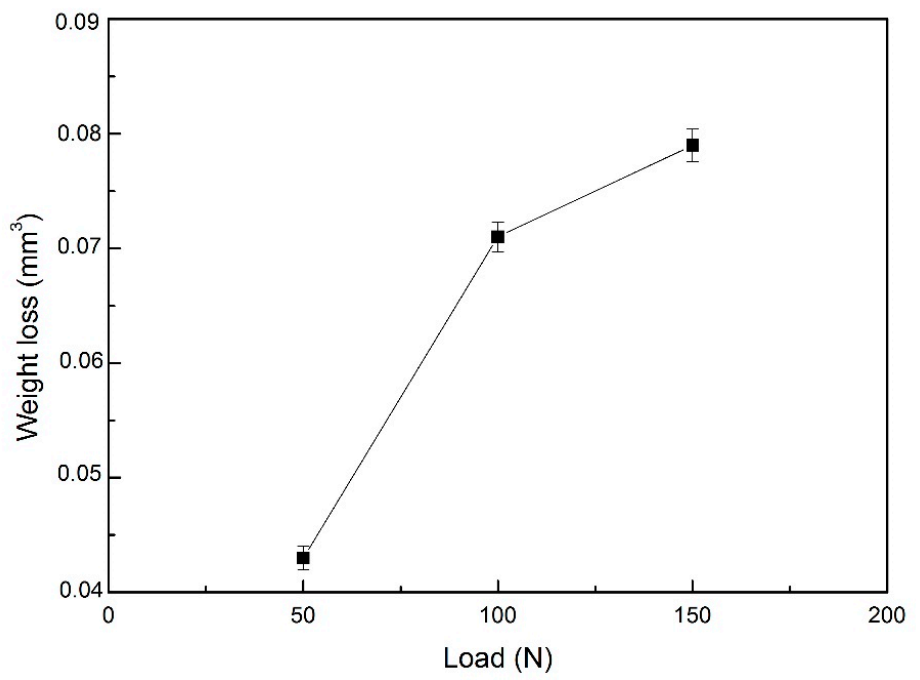

Figure 10. Weight loss as a function of the applied load.

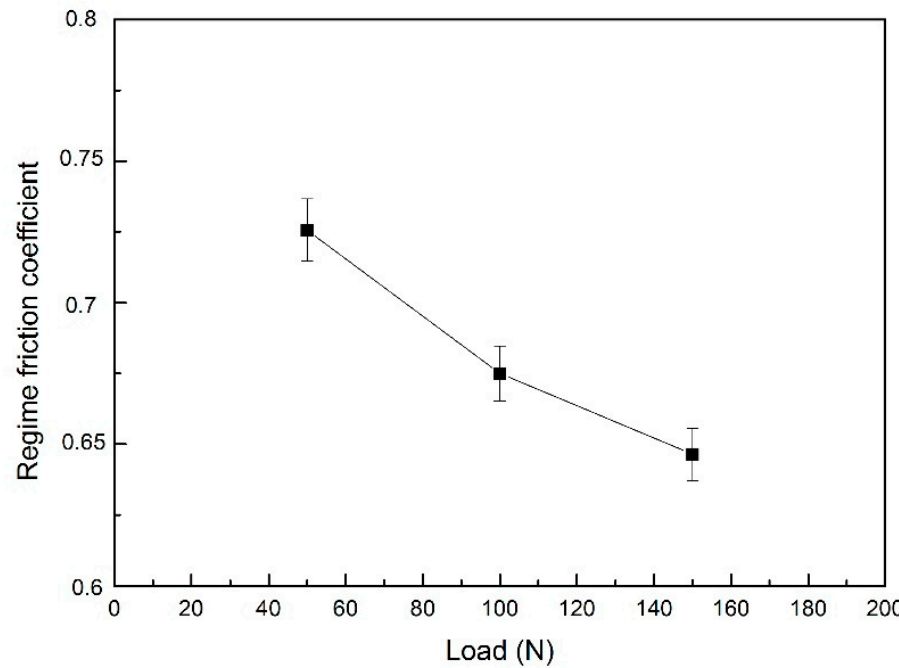

Figure 11. Friction coefficient as a function of the applied load.

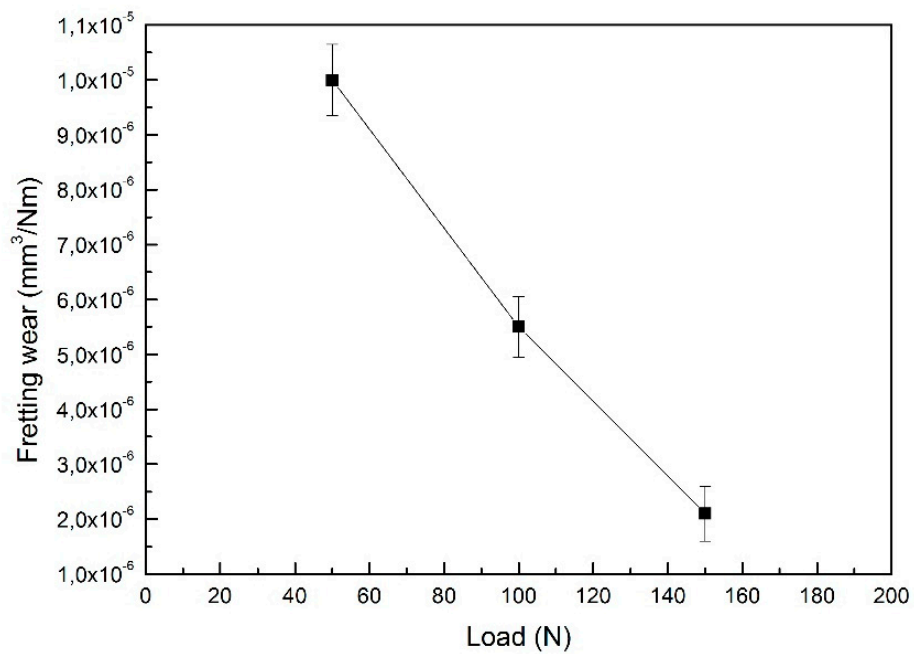

Figure 12. Fretting wear as a function of the applied load. 
The influence of hardness on fretting wear is still an open debate. Recent studies about fretting in hardened steels suggest that a slight hardness differential can reduce the damage and that a lower hardness increases the wear volume [32,33]. Other evidences focus on the effect of hardness on the fretting damage [34]. In the present study, the increase in hardness leads to a more hardened volume in action against the pin load, so the friction damage decreases as the material is more resistant in the inner layers. As the material under fretting is harder, the dissipated energy during the process increases revealing a more resistant structure against damage. As a main conclusion, for the cold sprayed coatings where the hardness varies from the surface to the substrate, both the volume loss and the fretting wear follows the same trend revealing a direct correlation between the nanoindentation results and the wear damage ones.

\section{Conclusions}

Inconel 625 nickel based superalloy particles were cold sprayed onto carbon steel in order to produce coatings with a nominal thickness of $500 \mu \mathrm{m}$. The processing conditions were selected in order to optimize the particles impact velocity to obtain low porosity coatings. The coatings hardness measured through nanoindentation revealed an increased material resistance by moving from the surface to the substrate, the nanoindentation hardness was 7.4 GPa on the polished coating surface and 11.5 at the coating-substrate interface. The scratch tests performed on the coating surface revealed the appearance of the first critical load at $9 \mathrm{~N}$ and $28 \mu \mathrm{m}$ depth with the formation of hairline cracks inclined between 30 and $40^{\circ}$ with respect to the scratch direction. The second critical load acted at 32 $\mathrm{N}$ and $82 \mu \mathrm{m}$ with the formation of cracks inside the crack track, the crack density increases as the vertical load increases. The third critical load at $44 \mathrm{~N}$ and $152 \mu \mathrm{m}$ is revealed by the starting of the coating delamination.

The fretting tests performed on the coating at different loads (50, 100 and $150 \mathrm{~N}$ ) showed that the volume loss is not linear but that its increase is reduced by increasing the maximum load. This was due to the increased material hardness by moving toward the substrate. This behaviour is confirmed by the analyses of the wear and fretting coefficients that decrease as the maximum load increases.

Author Contributions: Conceptualization, P.D.C.; investigation, A.R., D.V.; writing-original draft preparation, P.D.C.; writing-review and editing, P.D.C., A.R. and D.V.; SEM observations, L.C. All authors have read and agreed to the published version of the manuscript.

Funding: This research received no external funding.

Institutional Review Board Statement: Not applicable.

Informed Consent Statement: Not applicable.

Data Availability Statement: The data presented in this study are available on request from the corresponding author.

Conflicts of Interest: The authors declare no conflict of interest.

\section{References}

1. Cavaliere, P. Cold-Spray Coatings: Recent Trends and Future Perspectives; Springer: New York, NY, USA, 2018. [CrossRef]

2. Yin, S.; Cavaliere, P.; Aldwell, B.; Jenkins, R.; Liao, H.; Li, W.; Lupoi, R. Cold spray additive manufacturing and repair: Fundamentals and applications. Addit. Manuf. 2018, 21, 628-650. [CrossRef]

3. Assadi, H.; Gärtner, F.; Stoltenhoff, T.; Kreye, H. Bonding mechanism in cold gas spraying. Acta Mater. 2003, 51, 4379-4394. [CrossRef]

4. Rokni, M.R.; Nutt, S.R.; Widener, C.A.; Champagne, V.K.; Hrabe, R.H. Review of Relationship Between Particle Deformation, Coating Microstructure, and Properties in High-Pressure Cold Spray. J. Therm. Spray Technol. 2017, 26, 1308-1355. [CrossRef]

5. Silvello, A.; Cavaliere, P.D.; Albaladejo, V.; Martos, A.; Dosta, S.; Cano, I.G. Powder Properties and Processing Conditions Affecting Cold Spray Deposition. Coatings 2020, 10, 91. [CrossRef]

6. Cavaliere, P.; Silvello, A. Processing conditions affecting residual stresses and fatigue properties of cold spray deposits. Int. J. Adv. Manuf. Technol. 2015, 81, 1857-1862. [CrossRef] 
7. Xie, Y.; Planche, M.-P.; Raoelison, R.; Liao, H.; Suo, X.; Hervé, P. Effect of Substrate Preheating on Adhesive Strength of SS 316L Cold Spray Coatings. J. Therm. Spray Technol. 2016, 25, 123-130. [CrossRef]

8. Kim, K.; Watanabe, M.; Kuroda, S. Bonding mechanisms of thermally softened metallic powder particles and substrates impacted at high velocity. Surf. Coat. Technol. 2010, 204, 2175-2180. [CrossRef]

9. Hassani-Gangaraj, M.; Veysset, D.; Champagne, V.K.; Nelson, K.A.; Schuh, C.A. Adiabatic shear instability is not necessary for adhesion in cold spray. Acta Mater. 2018, 158, 430-439. [CrossRef]

10. Cavaliere, P.; Silvello, A. Finite element analyses of pure Ni cold spray particles impact related to coating crack behaviour. Surf. Eng. 2017, 34, 361-368. [CrossRef]

11. Cavaliere, P.; Perrone, A.; Silvello, A. Pure cobalt cold spray nanostructured coatings. J. Therm. Spray Technol. 2016, 25, 1168-1176. [CrossRef]

12. Cavaliere, P.; Perrone, A.; Silvello, A. Crystallization Evolution of Cold-Sprayed Pure Ni Coatings. J. Therm. Spray Technol. 2016, 25, 1158-1167. [CrossRef]

13. Yin, S.; Wang, X.; Suo, X.; Liao, H.; Guo, Z.; Li, W.; Coddet, C. Deposition behavior of thermally softened copper particles in cold spraying. Acta Mater. 2013, 61, 5105-5118. [CrossRef]

14. Cavaliere, P.; Silvello, A.; Cinca, N.; Canales, H.; Dosta, S.; Cano, I.G.; Guilemany, J. Microstructural and fatigue behavior of cold sprayed Ni-based superalloys coatings. Surf. Coat. Technol. 2017, 324, 390-402. [CrossRef]

15. Srinivasan, D.; Chandrasekhar, V.; Amuthan, R.; Lau, Y.C.; Calla, E. Characterization of Cold-Sprayed IN625 and NiCr Coatings. J. Therm. Spray Technol. 2016, 25, 725-744. [CrossRef]

16. Fantozzi, D.; Matikainen, V.; Uusitalo, M.; Koivuluoto, H.; Vuoristo, P. Chlorine-induced high temperature corrosion of Inconel 625 sprayed coatings deposited with different thermal spray techniques. Surf. Coat. Technol. 2017, 318, 233-243. [CrossRef]

17. Afsous, M.; Shafyei, A.; Soltani, M.; Eskandari, A. Characterization and Evaluation of Tribological Properties of NiCrBSi-Gr Composite Coatings Deposited on Stainless Steel 420 by HVOF. J. Therm. Spray Technol. 2020, 29, 773-788. [CrossRef]

18. Jia, Z.; Wang, Y.; Ji, J.; Sun, X. Fretting Wear Properties of Thermally Deformed Inconel 625 Alloy. Trans. Indian Inst. Met. 2020, 73, 2829-2839. [CrossRef]

19. Soria, S.R.; Tolley, A.; Yawny, A. Characterization of damage and triboparticles resulting from fretting of Incoloy 800 steam generator tubes against different materials. Wear 2017, 390-391, 198-208. [CrossRef]

20. Sirvent, P.; Garrido, M.A.; Lozano-Perez, S.; Poza, P. Oscillating and unidirectional sliding wear behaviour of cold sprayed Ti-6Al-4V coating on Ti-6Al-4V substrate. Surf. Coat. Technol. 2020, 382, 125152. [CrossRef]

21. Khun, N.W.; Tan, A.W.Y.; Liu, E. Mechanical and Tribological Properties of Cold-Sprayed Ti Coatings on Ti-6Al-4V Substrates. J. Therm. Spray Technol. 2016, 25, 715-724. [CrossRef]

22. Cavaliere, P. Mechanical properties of nanocrystalline metals and alloys studied via multi-step nanoindentation and finite element calculations. Mater. Sci. Eng. A 2009, 512, 1-9. [CrossRef]

23. Chen, Y.; Bakshi, S.R.; Agarwal, A. Correlation between nanoindentation and nanoscratch properties of carbon nanotube reinforced aluminum composite coatings. Surf. Coat. Technol. 2010, 204, 2709-2715. [CrossRef]

24. Kwon, J.-D.; Park, D.-K.; Woo, S.-W.; Yoon, D.-H.; Chung, I. A study on fretting fatigue life for the Inconel alloy 600 at high temperature. Nucl. Eng. Des. 2010, 240, 2521-2527. [CrossRef]

25. Silvello, A.; Cavaliere, P.; Rizzo, A.; Valerini, D.; Dosta, S.; Garcia Cano, I. Fatigue Bending Behavior of Cold-Sprayed Nickel-Based Superalloy Coatings. J. Therm. Spray Technol. 2019, 28, 930-938. [CrossRef]

26. Eason, P.D.; Fewkes, J.A.; Kennett, S.C.; Eden, T.J.; Tello, K.; Kaufman, M.J.; Tiryakioğlu, M. On the characterization of bulk copper produced by cold gas dynamic spray processing in as fabricated and annealed conditions. Mater. Sci. Eng. A 2011, 528, 8174-8178. [CrossRef]

27. Leyland, A.; Matthews, A. On the significance of the H/E ratio in wear control: A nanocomposite coating approach to optimised tribological behaviour. Wear 2000, 246, 1-11. [CrossRef]

28. Zawischa, M.; Makowski, S.; Schwarzer, N.; Weihnacht, V. Scratch resistance of superhard carbon coatings-A new approach to failure and adhesion evaluation. Surf. Coat. Technol. 2016, 308, 341-348. [CrossRef]

29. Valentini, R.; Cavaliere, P.; Valerini, D. Nanoindentation and scratch behaviour of Ni-P electroless coatings. Tribol. Mater. Surf. Interfaces 2020, 14, 22-32. [CrossRef]

30. Wang, Q.; Zhou, F.; Yan, J. Evaluating mechanical properties and crack resistance of CrN, CrTiN, CrAlN and CrTiAlN coatings by nanoindentation and scratch tests. Surf. Coat. Technol. 2016, 285, 203-213. [CrossRef]

31. Lavella, M. Contact Properties and Wear Behaviour of Nickel Based Superalloy René 80. Metals 2016, 6, 150. [CrossRef]

32. Budinski, K.G. Effect of hardness differential on metal-to-metal fretting damage. Wear 2013, 301, 501-507. [CrossRef]

33. Li, J.; Lu, Y.; Zhang, H.; Xin, L. Effect of grain size and hardness on fretting wear behavior of Inconel 600 alloys. Tribol. Int. 2015, 81, 215-222. [CrossRef]

34. Xin, L.; Yang, B.B.; Wang, Z.H.; Li, J.; Lu, Y.H.; Shoji, T. Microstructural evolution of subsurface on Inconel 690TT alloy subjected to fretting wear at elevated temperature. Mater. Des. 2016, 104, 152-161. [CrossRef] 